\title{
Effect of Welding Speed on Mechanical Properties of Friction Stir Welded Copper
}

\author{
L. Suvarna Raju, Dr. Adepu Kumar and Dr. P. Indreswaraiah
}

\begin{abstract}
Fusion welding of copper and its alloys tends to degrade the mechanical strength at the weld joint area due to high thermal diffusivity and high melting point. Friction Stir Welding (FSW) is an excellent alternative for joining of these materials against fusion joining. FSW is an emerging solid state joining process in which the material that is being welded does not melt and recast. This process uses a nonconsumable tool to generate frictional heat in the abutting surfaces. The main objective of this investigation is to use FSW for joining of $3 \mathrm{~mm}$ thick copper sheet using taper cylindrical tool pin profile. The defect free welds were obtained at a tool rotational speed of $900 \mathrm{rpm}$ and traverse speed of 25, 31.5 and $40 \mathrm{~mm} / \mathrm{min}$ respectively. Mechanical and microstructure analysis has been performed to evaluate the characteristics of friction stir welded copper. From the investigation it is found that the joints fabricated at a traverse speed of 40mm/min resulted in better mechanical properties compared to other traverse speeds. The tensile properties of all weld joints showed a relative correspondence to the variation of the hardness in the weld zone. The observed results were correlated with the microstructure and fracture features.
\end{abstract}

Keywords--- Friction Stir Welding, Copper, Mechanical properties, Microstructures, Fractography

\section{INTRODUCTION}

$\mathrm{C}$ OPPER and its alloys are the most important engineering materials due to their good ductility, corrosion resistance, electrical and thermal conductivity [1]. Welding of copper is usually difficult by conventional fusion welding processes as it has high thermal diffusivity (401W/m.K). FSW was invented at The Welding Institute (TWI), UK in 1991. It is one of the solid state welding process in which a non-consumable rotating welding tool pin is plunged into the joint line between the two plates that are to be welded together. The shoulder makes firm contact with the top surface of the work piece, so that the frictional heat is generated by the tool shoulder. Due to this frictional heat, surrounding material softens and allows the tool to be involved along the joint line [2]. The material is

L. Suvarna Raju, Mechanical Engineering Department, Kamala Institute of Technology \& Science (KITS), Huzurabad, India. Email:rajumst@gmail.com

Dr. Adepu Kumar, Mechanical Engineering Department, National Institute of Technology (NIT)

Warangal, India. E-mail:adepu_kumar7@yahoo.co.in

Dr. P. Indreswaraiah, Mechanical Engineering Department, Kamala Institute of Technology \& Science (KITS), Huzurabad, India

DOI: 10.9756/BIJIEMS.4821 plasticized and translated along the welding direction and this plasticized material is transported from the leading edge to the trailing edge of the tool where it is forged into a joint and leaving a solid phase bond between the two plates [3]. FSW is energy efficient, environmentally friendly, less distortion; faster welding speeds than traditional fusion welding techniques and to join materials that are difficult to fusion weld [4]. FSW creates the weld joint without bulk melting. In addition, the extensive thermo mechanical deformation induces dynamic recrystallization and recovery that refine the microstructure of the weld region. Therefore, welds made by FSW are shown to have much improved mechanical properties than the corresponding fusion welds. The copper used in containment canisters for nuclear waste has been manufactured via FSW process [5]. Fabrication of backing plates of copper alloys were used for the sputtering equipments [6]. Elangovan et al. [7] studied five tool profiles i.e Straight cylindrical, threaded cylindrical, taper cylindrical, square and triangular, for the welding of AA 60601 aluminium alloy and found that the square pin profiled tool produces defect free welds for all the axial forces used. Similarly, Lee et al. [2] achieved defect-free joining of 4-mm-thick copper plate at a rotation rate of $1250 \mathrm{rpm}$ and a traverse speed of 61 $\mathrm{mm} / \mathrm{min}$. Cavaliere et.al. [8] studied the effect of welding parameters on mechanical properties of AA6056 and found that tensile strength and ductility of the joints are influenced by rotation speed and welding speed. Okamato et.al.[5] fabricated a copper backing plate for cooling by FSW at a tool rotation speed of $1300 \mathrm{rpm}$ with a welding speed of 170 $\mathrm{mm} / \mathrm{min}$. Sakthivel and Mukhopadhya [9] obtained FSW welds of $2 \mathrm{~mm}$ thick copper sheet at a tool rotations speed of $1000 \mathrm{rpm}$ with a welding speed of $30 \mathrm{~mm} / \mathrm{min}$. However, due to the presence of larger grains within the joints resulted from high tool rotation speed, the efficiency of the joint strength decreased.

In this present study we explored the FSW of pure copper. The characterization of friction stir weldments of copper was carried out and correlated with their microstructure and fracture features.

\section{EXPERIMENTAL PROCEDURE}

The copper rolled plates of $3 \mathrm{~mm}$ thickness were cut into the required size $(200 \mathrm{~mm} \times 100 \mathrm{~mm})$ by power hacksaw cutting and milling. The joint was obtained by butting the two plates and stirring them together with a rotating tool assembly by using vertical milling machine. Schematic sketch of the weld joint and tool is as shown in Fig.1. A non-consumable H13 tool steel with flat shoulder is chosen as tool material to fabricate the joints, because of its high strength at elevated temperature, thermal fatigue resistance and low wear 
resistance. The diameter of the shoulder and pin used were $24 \mathrm{~mm}, 8 \mathrm{~mm}$ respectively and length of the pin is $2.8 \mathrm{~mm}$. The butted plates were clamped on a steel backing plate. The welding tool is tilted by 3 degree of angle with reference to the welded plates and tool was rotated in the clockwise direction. A constant axial force is applied for all the joints. The FSW joints were fabricated with taper cylindrical tool pin profile and found to be defect free welds, the surface morphologies of the FSW joints were shown in Fig. 2.

Specimens for tensile testing were taken in transverse to the weld direction and machined as per ASTM E8/E8M-11 standards. Tensile test was conducted using computer controlled universal testing machine (Model: Autograph, Make: Shimatzu) with a cross head speed of $0.5 \mathrm{~mm} / \mathrm{min}$. Specimens for impact testing were taken in transverse to the weld direction and machined as per ASTM A370 standards. The charpy ' $\mathrm{V}$ ' notch impact test was conducted at room temperature using pendulum type impact testing machine. The amount of energy absorbed in fracture was recorded and the absorbed energy is defined as the impact toughness of the material. The Schematic sketch of tensile and impact specimens were shown in Fig.3. Specimens were cut at the middle of the joints in transverse direction for conducting micro hardness survey. Micro hardness test was carried out using Vickers digital micro hardness tester (Model: Autograph, Make: Shimatzu) with a $10 \mathrm{~g}$ load for $10 \mathrm{~s}$ duration. The microhardness was measured at an interval of $0.15 \mathrm{~mm}$ across the WZ, Thermo-Mechanical Affected Zone (TMAZ), Heat-Affected Zone (HAZ) and (base metal) BM.

Defect free welds were obtained at all the conditions such as tool rotation speed at $900 \mathrm{rpm}$ and weld speed at 25, 31.5 and $40 \mathrm{~mm} / \mathrm{min}$.

The microstructure at the weld zone of friction stir welded joint at the condition of weld speed at $40 \mathrm{~mm} / \mathrm{min}$ is observed to be having finer grains than that of other weld conditions due to dynamic recrystallization.

The joints made with tool rotation speed at 900rpm and weld speed at $40 \mathrm{~mm} / \mathrm{min}$ resulted in good mechanical properties as compared with other weld conditions due to sufficient heat generation and proper mixing of the material in the weld zone.

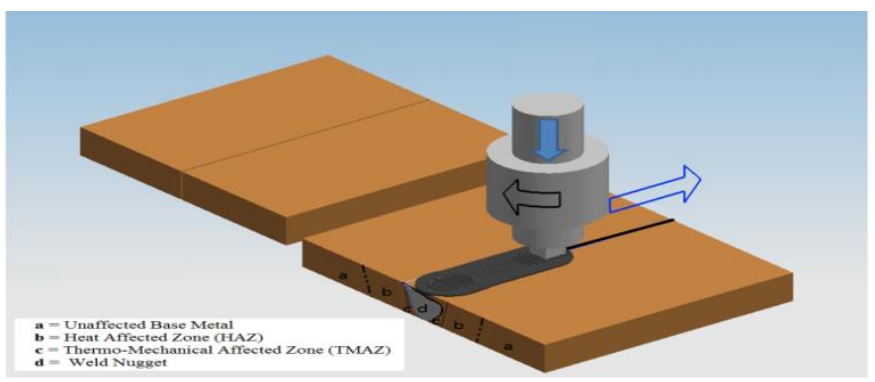

Fig.1: Schematic Sketch of Friction Stir Welding showing the Various Characteristic Regions

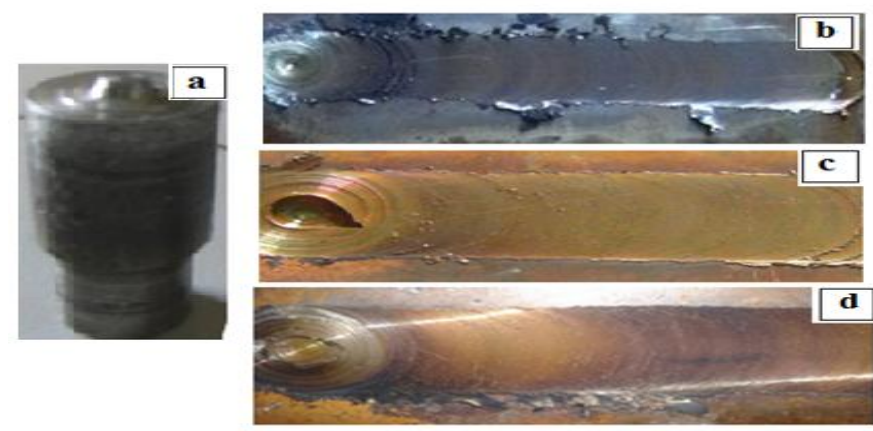

Fig. 2: Typical Photograph of a Manufactured Tool (a) Taper Cylindrical Tool Pin Profile and Surface Morphology of the Joints at Various Conditions: (b) $900 \mathrm{rpm}, 25 \mathrm{~mm} / \mathrm{min}$ (c) 900 $\mathrm{rpm}, 31.5 \mathrm{~mm} / \mathrm{min}$ (c) $900 \mathrm{rpm}, 40 \mathrm{~mm} / \mathrm{min}$

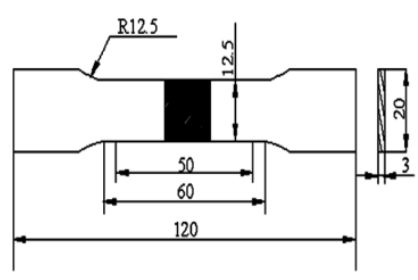

(a)

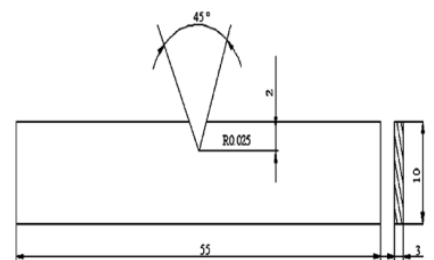

(b)
Fig. 3: Schematic Sketch of (a) Tensile Specimen

(b) Impact Specimen

\section{RESULTS AND DISCUSSION}

\section{A. Microstructure Studies}

In conventional welding of copper and aluminum alloys, the defects like porosity, slag inclusion, solidification on crack, etc. deteriorates the weld quality and weld joint properties. However, using FSW the joints are free from these defects since there is no melting takes place during the welding and metals are joined in the solid state itself due to the heat generated by the friction and flow of the metal influenced by the stirring action.

The specimens for metallographic examination were sectioned to the required size from the FSW joints transverse to the welding direction, polished and then etched with a solution of $100 \mathrm{ml}$ distilled water, $15 \mathrm{ml} \mathrm{HCl}$ and $2.5 \mathrm{~g}$ ferric chloride. The micro structural changes from the weld zone to the unaffected base metal were examined with optical microscopy (Model: NIKON; make Epiphot 200). The microstructure of the friction stir welded copper joint consists of different zones such as (a) weld zone (b) thermo mechanical affected zone (c) heat affected zone. The formation of above regions is affected by the material flow behavior under the influence of welding speeds with rotating non consumable tool. The optical microstructure of the weld zone at different weld speeds with constant tool rotation speed are displayed in Fig.4. From the observed microstructure, the joints fabricated at the condition with the tool rotation speed of 900rpm and weld speed of $40 \mathrm{~mm} / \mathrm{min}$ observed to be having finer grains compared to other conditions. This refinement is due to the dynamic recrystallization caused by simultaneously received plastic shear deformation and 
frictional heat $[10,11]$. Dynamic recrystallization is of great industrial interest due to the new grains being smaller than the initial grains and thereby having improved mechanical properties at room temperature.

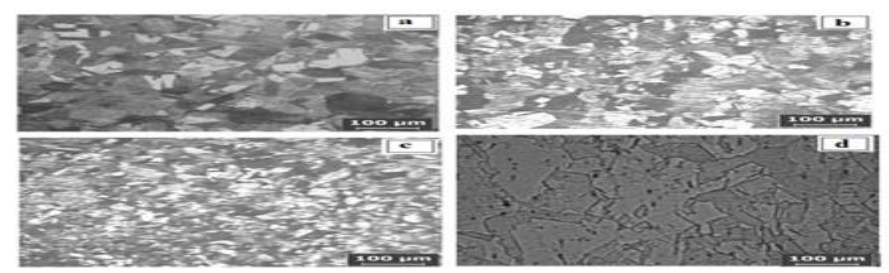

Fig. 4: Microstructure of Weld Zones of FSW Joints at Various Conditions: (a) $900 \mathrm{rpm}, 25 \mathrm{~mm} / \mathrm{min}$ (b) $900 \mathrm{rpm}$, $31.5 \mathrm{~mm} / \mathrm{min}$ and (c) $900 \mathrm{rpm}, 40 \mathrm{~mm} / \mathrm{min}$ (d) Base Metal

\section{B. Mechanical Properties}

Mechanical properties such as yield strength, tensile strength and percentage of elongation have been evaluated. At each condition three specimens were tested and average of the results of three specimens is presented. Table 1 shows the tensile properties for base metal and Table 2 shows mechanical properties of the copper weldments. From the experimental result, at the tool rotation speed of $900 \mathrm{rpm}$ and weld speed of $40 \mathrm{~mm} / \mathrm{min}$ exhibited better tensile and impact properties and the joint efficiency (65\%) is also higher as compared to other conditions.

Table I: Mechanical Properties of Base Metal

\begin{tabular}{|c|c|c|c|c|c|}
\hline Material & $\begin{array}{c}\text { UTS } \\
(\mathrm{MPa})\end{array}$ & $\begin{array}{c}\mathrm{YS} \\
(\mathrm{MPa})\end{array}$ & $\% \mathrm{El}$ & $\begin{array}{c}\text { Micro } \\
\text { hardness } \\
(\mathrm{HV})\end{array}$ & $\begin{array}{c}\text { Impact } \\
\text { Strength } \\
(\mathrm{J})\end{array}$ \\
\hline $\begin{array}{c}\text { Pure } \\
\text { copper }\end{array}$ & 260 & 231 & 31 & 110 & 18 \\
\hline
\end{tabular}

\section{a. Effect of Welding Speed}

The translation of tool moves the stirred material from the leading side to the trailing side of the tool pin. The rate of heating of thermal cycle during FSW is a strong function of the welding speed. A significant increase in welding speed is achieved with high weld quality and excellent weld joint properties. The softened area is narrower for the higher welding speed than that for the lower welding speed. Thus, the tensile strength of copper weldments has a proportional relationship with welding speed. The joints fabricated by tool rotation speed at $900 \mathrm{rpm}$ and weld speed at $40 \mathrm{~mm} / \mathrm{min}$ obtained higher tensile strength than other conditions. This is due to the intense plastic deformation and sufficient frictional heat generation in the weld zone. At lower welding speed (i.e. 25 and $31.5 \mathrm{~mm} / \mathrm{min}$ ) resulted in higher temperature and slower cooling rate in the processed zone causes grain growth which results in decrease in strength and hardness.

Table II: Mechanical Properties of Friction Stir Welded Copper

\begin{tabular}{ccccccc}
\hline $\begin{array}{c}\text { Tool rotation } \\
\text { speed }(\mathrm{rpm})\end{array}$ & $\begin{array}{c}\text { Weld speed } \\
(\mathrm{mm} / \mathrm{min})\end{array}$ & $\begin{array}{c}\text { UTS } \\
(\mathrm{MPa})\end{array}$ & $\begin{array}{c}\text { YS } \\
(\mathrm{MPa})\end{array}$ & \begin{tabular}{c}
$\% \mathrm{EL}$ \\
\hline 900
\end{tabular} & $\begin{array}{c}\text { Micro hardness } \\
(\mathrm{HV})\end{array}$ & $\begin{array}{c}\text { Impact } \\
\text { strength } \\
(\mathrm{J})\end{array}$ \\
\hline 900 & 31.5 & 135 & 102 & 9.1 & 62 & 8 \\
\hline 900 & 40 & 168 & 109 & 13.5 & 85 & 8 \\
\hline
\end{tabular}

Hence, the welding speed must be optimized to improve the joint properties. The percentage of elongation is lower than that of the base metal due to the increase in deformation resistance.

The hardness profiles evaluated across the weld nugget at different conditions is shown in Fig.5. The hardness of the base metal is $110 \mathrm{HV}$. The hardness of the nugget zone is influenced by annealing softening and grain refinement in pure metals [2]. The average hardness of weld zone is found to be significantly lower than that of the hardness of base metal. In Harries and Norman's work, it is suggested that the variation of the micro hardness values in the welded area and base metal is due to the difference between the microstructure of the base metal and weld zone [12]. However, in the present study the hardness of the weld zones fabricated by tool rotation speed at $900 \mathrm{rpm}$ and weld speed at $40 \mathrm{~mm} / \mathrm{min}$ found to be $85 \mathrm{Hv}$ which is higher than that of other conditions. This is due to the presence of very finer grains at the weld nugget. The weld center has slightly lower hardness than that of the base metal in spite of smaller grain size.

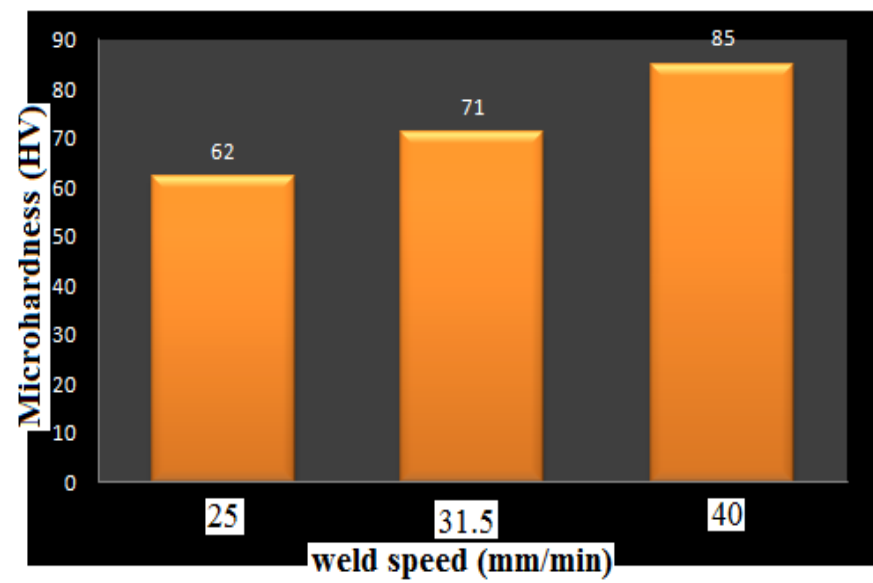

Fig. 5: Micro Hardness of FSW Joints for Different Weld Speeds

\section{Fractography}

The fractural morphology of the tensile and impact specimens of the fracture surface of the weld joints were studied using the scanning electron microscopy (SEM) to understand the mode of failure. Fractured features of the weld joints are shown in Fig.6 and Fig.7. The dimple pattern is observed in the whole width of the specimen. All joints were failed on the retreating side during tensile testing where hardness value is lowest.

The joints fabricated at the condition of tool rotation speed at $900 \mathrm{rpm}$ and weld speed at $40 \mathrm{~mm} / \mathrm{min}$ exhibited superior ductility as compared with other conditions. This is due to presence of tiny shallow dimples and also some large dimples resulted from micro dimples coalescence. It could be attributed to the high plastic deformation which indicates more intense ductile fracture. 

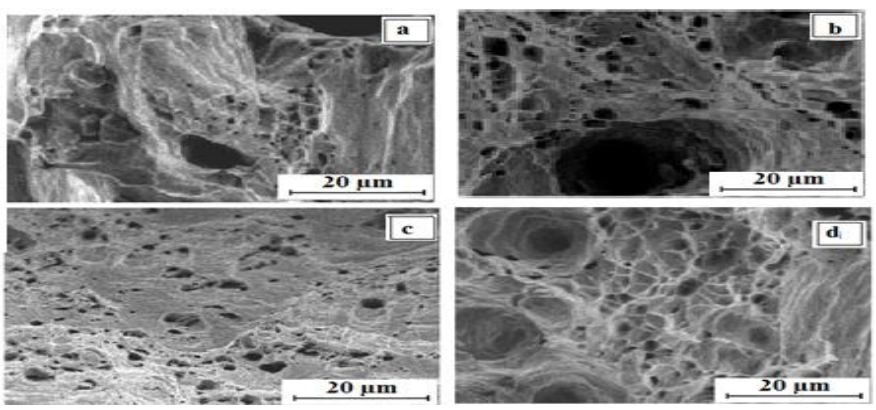

Fig. 6: Fracture Surface of Tensile Specimens at Various Conditions: (a) $900 \mathrm{rpm}, 25 \mathrm{~mm} / \mathrm{min}$,(b) $900 \mathrm{rpm}, 31.5$ $\mathrm{mm} / \mathrm{min}$ (c) $900 \mathrm{rpm}, 40 \mathrm{~mm} / \mathrm{min}$ and (d) Base Metal
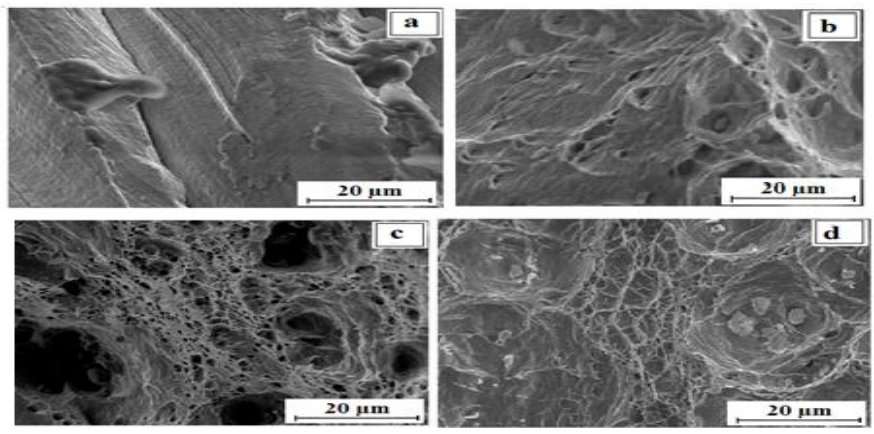

Fig. 7: Fracture Surface of Impact Specimens at Various Conditions: (a) $900 \mathrm{rpm}, 25 \mathrm{~mm} / \mathrm{min}$,(b) $900 \mathrm{rpm}, 31.5$ $\mathrm{mm} / \mathrm{min}$ (c) $900 \mathrm{rpm}, 40 \mathrm{~mm} / \mathrm{min}$ and (d) base Metal

\section{CONCLUSION}

The mechanical properties of pure copper weldments made by FSW were investigated. The following conclusions can be drawn. The weldments made by FSW at the tool rotation speed of 900rpm and weld speed of $40 \mathrm{~mm} / \mathrm{min}$ exhibited better mechanical properties. This is due to sufficient heat generation and proper mixing of the material in the weld zone. Further it is also observed that finer grains were formed in the weld zone which is due to dynamic recrystallization. The fracture surface of both tensile and impact specimens shows fine dimples at weld zone of copper weldments.

\section{ACKNOWLEDGMENT}

The authors would like to thank the authorities of National Institute of Technology (NIT), Warangal, NIT-Calicut and Indian Institute of Chemical Technology (IICT), Hyderabad, India for providing the facilities to carry out this work

\section{REFERENCES}

[1] Chinese Welding Society: Welding Handbook, 2nd ed., China Machine Press, Beijing, vol. 2, Pp. 608-643, 2001.

[2] W. B.Lee and S.B.Jung. "The joint properties of copper by friction stir welding" Mater.Lett. Vol 58, Pp.1041-1046, 2004.

[3] J.Q.Su, T.W.Nelson, R.Mishra and M.Mahoney, "Microstructural investigation of friction stir welded 7050-T651 aluminium", Acta Mater. Vol. 51(3), Pp.713-729, 2003.

[4] C.Genevois, A. Deschamps, A. Denquin, and B. Doisneau-Cottignies, "Quantitative investigation of precipitation and mechanical behaviour for AA2024 friction stir welds", Acta Mater, Vol.53, Pp.2447-2458, 2005.

[5] K. Okamoto, M. Doi, S. Hirano, K. Aota, H. Okamura, Y. Aono, and T.C. Ping., "Fabrication of backing plate of copper alloy by friction stir
welding"[CD-ROM]. Proc. 3rd Int. Symp.on Friction Stir Welding, Kobe, Japan, 2001, september 27-28.

[6] M.K. Yadaya, R.S Mishra, Y.L.Chen, B. Carlson and G.J Grant, "study of friction stir welding of thin aluminium sheets in lap joint configuration”, Sci. Technol.weld.Joinn, Vol.15(1), Pp70-75,Pp 2010.

[7] K Elangovan, V Balasubramanian and M.Vallipan. "Influences of tool pin profile and axial force on the formation of friction stir processing zone in AA6061 aluminium alloy", Int. J. Adv. Mannuf. Technol.Vol.38(3-4), Pp 285-295, 2008.

[8] P Cavaliere, G Campanile, Panella F,Squillace A. "Effect of welding parameters on mechanical and microstructural properties of AA6056 joints produced by friction stir welding", J Mater Process Technol 2006, Vol.180, Pp263-270, 2006.

[9] T Sakthivel, J Mukhopadhya, "Microstructure and mechanical properties of friction stir welded copper" J Mater Sci, Vol.42(19), Pp.8126-8129, 2007.

[10] Y.S. Sato, S.H.C. Park, H. Kokawa. "Microstructural Factors Governing Hardness in Friction-Stir-Welds of Solid-Solution-Hardened Al Alloys". Metall. Mater. Trans. A, Vol.32A-12,Pp.3032-3042, 2001.

[11] K.V. Jata and S.L. Semiatin. "Continuous Dynamic recrystallization during friction stir welding of high strength aluminum alloys". Scripta Mater.Vol.43, Pp.743-749, 2000.

[12] D Harris, A F Norman, "Properties of Friction Stir Welded joints: A review of the literature, E U POSTIR", program report presented at the $6^{\text {th }}$ PSG meeting, 17-18 June 2003 